\title{
Feasibility study of a novel hot stamping process for Ti6Al4V alloy
}

\author{
Mateusz Kopec ${ }^{l, 3}$, Kehuan Wang ${ }^{l}$, Yaoqi Wang ${ }^{2}$, Liliang Wang ${ }^{1}$, and Jianguo Lin ${ }^{l}$ \\ ${ }^{1}$ Department of Mechanical Engineering, Imperial College London, London SW7 2AZ, UK \\ ${ }^{2}$ Beijing Aeronautical Manufacturing Technology Research Institute,Beijing 100024, China \\ ${ }^{3}$ Institute of Fundamental Technological Research Polish Academy of Sciences, 02-106 Warsaw, Pawinskiego 5B, Poland
}

\begin{abstract}
To investigate the feasibility of a novel hot stamping process for the Ti6Al4V titanium alloy using low temperature forming tools, mechanical properties of the material were studied using hot tensile tests at a temperature range of $600-900^{\circ} \mathrm{C}$ with a constant strain rate of $1 \mathrm{~s}^{-1}$. Hot stamping tests were carried out to verify the feasibility of this technology and identify the forming window for the material. Results show that when the deformation temperature was lower than $700^{\circ} \mathrm{C}$, the amount of elongation was less than $20 \%$, and it also had little change with the temperature. However, when the temperature was higher than $700^{\circ} \mathrm{C}$, a good ductility of the material can be achieved. During the forming tests, parts failed at lower temperatures $\left(600^{\circ} \mathrm{C}\right)$ due to the limited formability and also failed at higher temperatures $\left(950^{\circ} \mathrm{C}\right)$ due to the phase transformation. The post-form hardness firstly decreased with the temperature increasing due to recovery and then increased due to the phase transformation. Qualified parts were formed successfully between temperatures of $750-850^{\circ} \mathrm{C}$, which indicates that this new technology has a great potential in forming titanium alloys sheet components.
\end{abstract}

Key words: titanium, hot stamping, metal forming

\section{Introduction}

In order to meet fuel consumption targets for the aviation sector, increasing demands for low density and high strength materials were observed. Due to applications of such lightweight materials in aircraft vehicles, a considerable weight reduction could be achieved [1]. Therefore, titanium alloys are found in aircraft applications because of the combination of weight, strength, corrosion resistance and temperature stability [2]. However, titanium alloys are considered as difficultto-form materials thus the forming of complex-shaped components is time, energy and cost intensive. Only a few conventional techniques could enable aircraft companies to produce qualified complex-shaped components. Superplastic forming is definitely one of the leading titanium forming techniques. Other known techniques including superplastic forming with diffusion bonding, hot stretch forming, creep forming, hot gas-pressure forming or isothermal hot forming [2]. It is unquestionable that components formed by these techniques have a high quality, however these components are achieved under conditions of a very high temperature, slow strain rate and simultaneous heating of tools and sheet during the process. As a result, the low efficiency of the forming process and simultaneous high production cost are observed. Recent development of forming technologies such as the solution heat treatment, forming and in-die quenching (HFQ) [3], the Quickplastic forming [4], and the hot stamping using rapid heating [5] could lead to the increase of productivity and become an alternative to conventionally used techniques. Hamedon et al. [6] proposed a hot stamping process to form titanium components from sheet metal utilizing cold dies and resistance heating. This solution led to the reduction of the tool wear and is more efficient and economical in comparison to conventionally used isothermal hot forming techniques. However, this technology was validated by forming a simple U-shaped component under resistance heating condition.

In order to further study the feasibility of hot stamping process for titanium alloys under furnace heating condition, the hot stamping tests of Ti6Al4V titanium alloy utilizing low temperature forming tools (used at

\footnotetext{
* Corresponding author: liliang.wang@imperial.ac.uk
} 
room temperature) and a hot blank was carried out. To investigate the formability of Ti6Al4V alloy, the uniaxial tensile tests were performed at temperatures ranging from $600^{\circ} \mathrm{C}$ to $900^{\circ} \mathrm{C}$ with constant strain rate of $1 \mathrm{~s}^{-1}$. Ti6Al4V components were successfully formed at temperatures ranging from of $750^{\circ} \mathrm{C}$ to $850^{\circ} \mathrm{C}$. Microstructure of formed components was characterized by Scanning Electron Microscope (SEM).

It was found that this new technology has a great potential in forming titanium alloys sheet components and a qualified part could be formed successfully. Proposed hot stamping process to form components from sheet metal using cold dies, promises to be a more efficient and economical process than the traditionally used isothermal hot forming techniques [6]. Moreover the post-form mechanical properties and microstructure can be tailored by the adjustment of heating temperature and application of low temperature forming.

\section{Experimental details}

\subsection{Uniaxial tensile test and microstructure examination}

Ti6Al4V titanium alloy sheet with initial thickness of 1.5 $\mathrm{mm}$ is used throughout the research. A Gleeble 3800 thermo-mechanical testing machine was used to characterize the properties of material through uniaxial tensile test at elevated temperatures. Dog-bone shaped specimens with a gauge length of $46 \mathrm{~mm}$, a width of 12 $\mathrm{mm}$ and a thickness of $1.5 \mathrm{~mm}$ were used. During the tests, flat samples were heated up with the heating rate of $2^{\circ} \mathrm{C} / \mathrm{s}$ to the testing temperatures ranging from $600^{\circ} \mathrm{C}$ to $900^{\circ} \mathrm{C}$ and deformed. After tensile tests, samples were air quenched immediately. Hardness of the samples after hot forming tests was measured using Vickers hardness tester. Hardness tests were carried out at room temperature by applying $10 \mathrm{kgf}$ load on indenter for 10 seconds. Microstructures were examined via scanning electron microscopy (SEM) using backscattered electron (BSE) mode. Metallographic specimens were prepared by standard mechanical polishing method.

\subsection{Hot forming test}

The forming tests on the titanium alloy were conducted using a 250 tonne Instron press (Fig.1). Rectangular samples of Ti6Al4V with dimension of $90 \times 8 \times 1.5 \mathrm{~mm}$ were first heated in the furnace to the target temperatures ranging from $600^{\circ} \mathrm{C}$ to $950^{\circ} \mathrm{C}$. Temperature of the samples was monitored using a thermocouple wire attached to them. After reaching the target temperature, the sample was quickly placed in the tool for 10 seconds, which was stamped at a speed of $10 \mathrm{~mm} / \mathrm{s}$ when the press was activated. The formed part was held in the low temperature die after forming to quench it to room temperature.
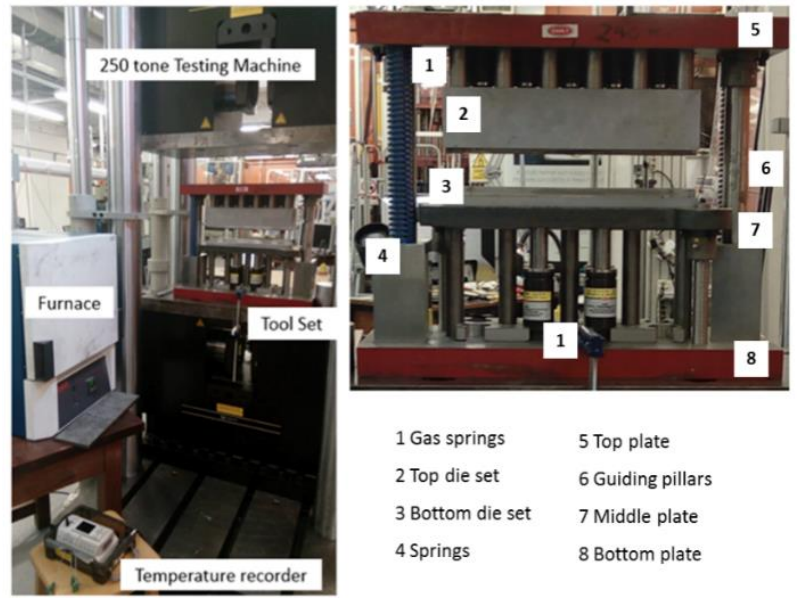

Fig. 1. Testing setup.

\section{Results \& discussion}

\subsection{Effect of heating temperature and strain rate on mechanical properties of Ti6AI4V alloy}

In order to determine the best forming condition, tensile tests were conducted at temperatures ranging from $600^{\circ} \mathrm{C}$ to $900^{\circ} \mathrm{C}$ with a constant strain rate of $1 \mathrm{~s}^{-1}$ (Fig.2). Simultaneous increase of elongation with the temperature was observed. Strain hardening could be found during deformation at temperatures ranging from $600^{\circ} \mathrm{C}$ to $700^{\circ} \mathrm{C}$, but only slight change in elongation was found. However, over the temperature of $700^{\circ} \mathrm{C}$, material softening and subsequent increase of elongation from $20 \%$ to $60 \%$ at $900^{\circ} \mathrm{C}$ were observed (Fig.3). High temperatures enhance dislocation mobility resulting in ductility increase during deformation. It was concluded that the investigated titanium alloy has a good formability over the temperature of $700^{\circ} \mathrm{C}$.

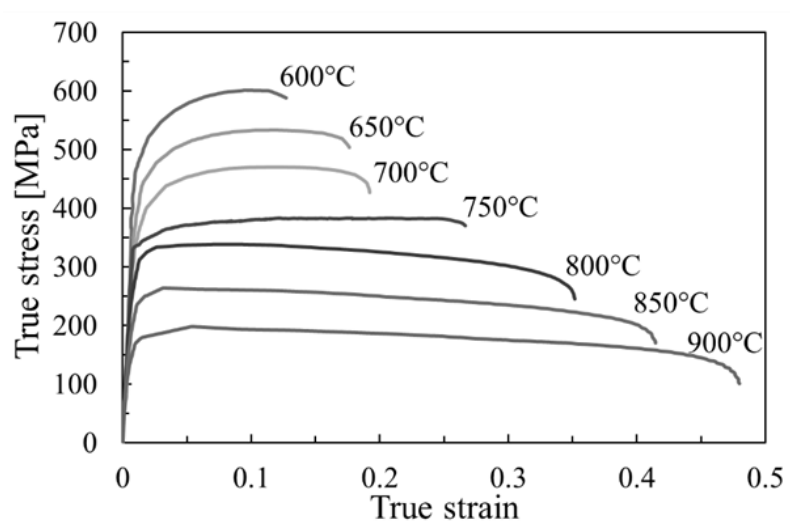

Fig. 2. Representative flow stress - strain curves of Ti6A14V titanium samples tested under the range of $600-900^{\circ} \mathrm{C}$. 


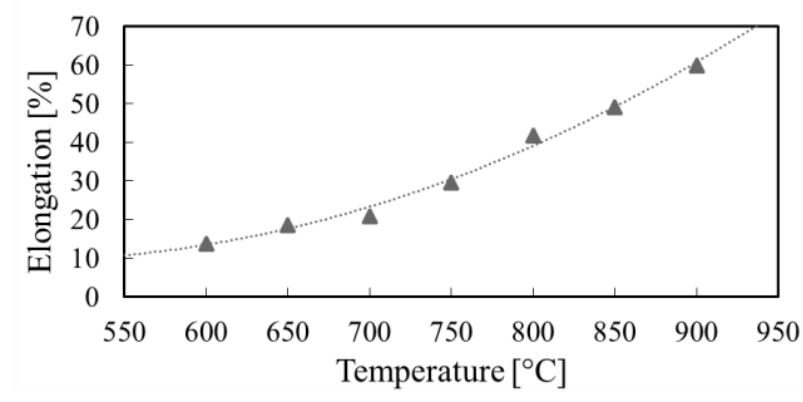

Fig. 3. Variations of elongation of Ti6Al4V titanium alloy with heating temperature obtained by tensile test.

Satisfactory elongation of investigated material $(>30 \%)$ was observed during testing at temperatures ranging from $750^{\circ} \mathrm{C}$ to $900^{\circ} \mathrm{C}$. In order to investigate the effect of strain rate on material property, tensile tests were carried out at temperatures of $750^{\circ} \mathrm{C}-850^{\circ} \mathrm{C}$, strain rates of $0.1 \mathrm{~s}^{-1}-5 \mathrm{~s}^{-}$ 1 and the same heating rate of $2^{\circ} \mathrm{C} / \mathrm{s}$. Evolution of elongation with the different strain rates was presented in Fig.4. It could be observed that the elongation increased with the increasing temperature from $0.2-0.35$ at $750^{\circ} \mathrm{C}$ to $0.5-0.6$ at $850^{\circ} \mathrm{C}$ and decreasing strain rate from 0.2 at strain rate of $5 \mathrm{~s}^{-1}$ to 0.35 at strain rate of $0.1 \mathrm{~s}^{-1}$ (at testing temperature of $750^{\circ} \mathrm{C}$ ). The same tendency is observed for temperatures of $800^{\circ} \mathrm{C}$ and $850^{\circ} \mathrm{C}$.

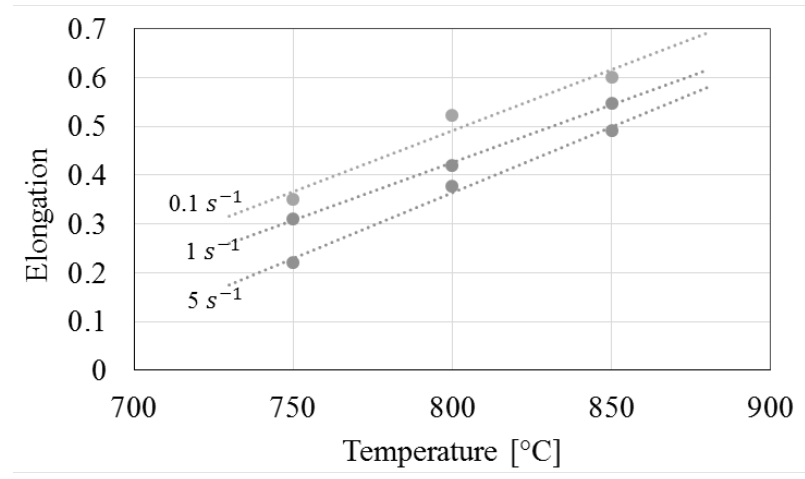

Fig. 4. Elongation evolution of Ti6Al4V titanium samples tested under different strain rates at temperatures ranging from 750 $850^{\circ} \mathrm{C}$.

\subsection{Hot forming of Ti6Al4V}

During the hot stamping of titanium alloys, three main stages may be distinguished: heating, transferring, and forming and quenching (Fig.5). The effective control of temperature at each stage is required since the temperature affects not only the formability of the material during deformation but also the post-form properties of the formed component. In order to monitor the temperature evolution during the whole process, a thermocouple wire was attached to the specimen. At the first stage, titanium sample was heated to the targeted temperature and then soaked within $180 \mathrm{~s}$, until the temperature became stable. Then, titanium sample was placed in the tool, stamped by low temperature dies and quenched to room temperature within tool. a)

b) Press Gas Press

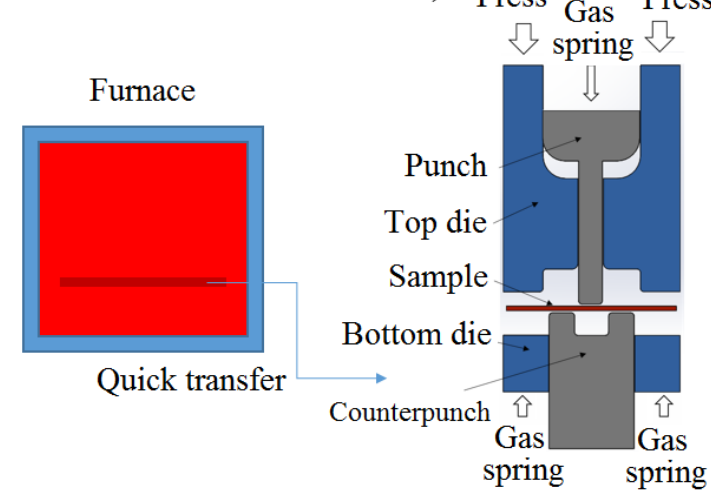

c)

Heating

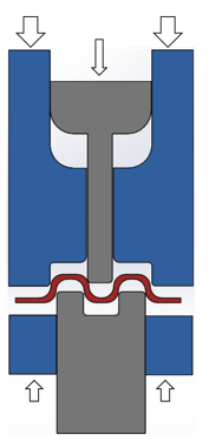

Forming \& quenching Stage I

d)

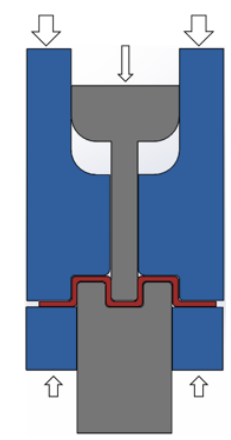

Forming \& quenching Stage II

Fig. 5. Schema of the forming process during heating of the sample (a), at the positioning stage (b), during forming (c) and at the final stage (d).

Ti6Al4V components formed at temperatures ranging from $600^{\circ} \mathrm{C}$ to $950^{\circ} \mathrm{C}$ on hydraulic press utilizing low temperature forming tools are shown in Fig.6a-e. However, parts were successfully formed only in the temperature range of $750^{\circ} \mathrm{C}$ to $850^{\circ} \mathrm{C}$. Macroscopic observations reveal that sample formed at $600^{\circ} \mathrm{C}$ has cracks on the surface. The occurrence of cracks is probably caused by the limited ductility of the material (Fig.7a). Evident cracks were also observed in feature formed at $900^{\circ} \mathrm{C}$ as shown in Fig. $7 b$. As the heating temperature reached $950^{\circ} \mathrm{C}$, the forming also failed resulting in the fracture of the sample into pieces (Fig.6e). It was found that during the uniaxial tensile test, elongation increased with the temperature increasing. However, the uniaxial tensile tests were performed at isothermal conditions. During actual forming, there is a considerable drop of temperature during the transferring and the forming. Because the microstructure and mechanical properties of material are strongly temperature dependent, such a drop of temperature led to decrease of formability. 


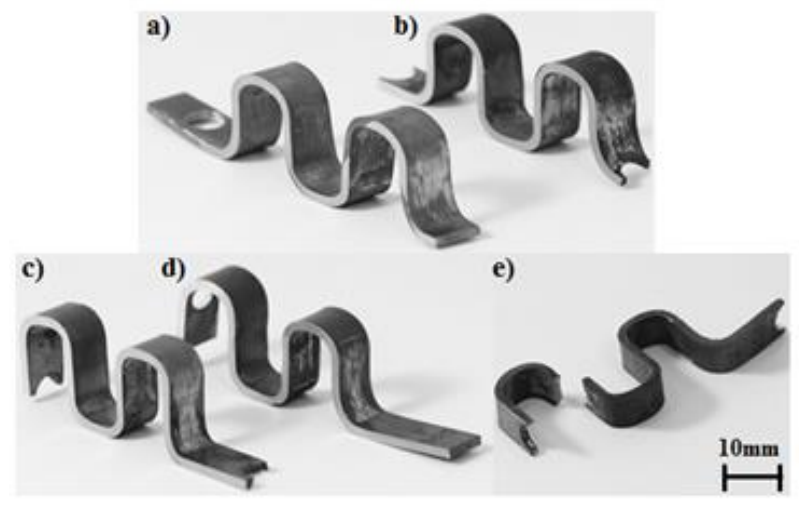

Fig. 6. View of parts formed at $600^{\circ} \mathrm{C}(\mathrm{a}), 750^{\circ} \mathrm{C}(\mathrm{b}), 850^{\circ} \mathrm{C}$ (c), $900^{\circ} \mathrm{C}(\mathrm{d})$, and $950^{\circ} \mathrm{C}(\mathrm{e})$.
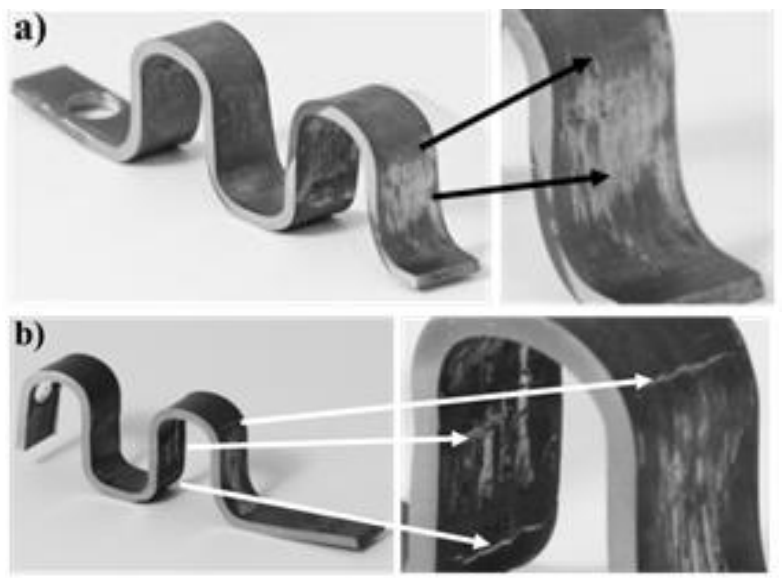

Fig. 7. View of cracks of parts formed at $600^{\circ} \mathrm{C}$ (a) and $900^{\circ} \mathrm{C}$ (b).

\subsection{Effect of hot stamping conditions on post- form properties of the formed components}

In order to investigate the effect of heating temperature on the post-form hardness and microstructure of the asformed part, hardness tests and SEM observations were conducted on shaped components. Hardness measurements were performed in the longitudinal direction of formed parts as it shown in Fig. 8. For each part, 20 indentations were used for calculation of an average hardness value. It could be observed that the hardness values firstly decreased from $356 \mathrm{HV} 10$ to $341 \mathrm{HV} 10$ at $750^{\circ} \mathrm{C}$, and then increased to $392 \mathrm{HV} 10$ at $950^{\circ} \mathrm{C}$ (Fig.8). It was concluded that during forming at temperatures up to $950^{\circ} \mathrm{C}$, phase transformation occurred and the content of $\beta$-phase increased significantly as shown in Fig.9. As the sample was cooled within low temperature dies, transformed beta phase and secondary $\alpha^{6}$ phase formed, which improved the hardness of the material at the room temperature (Fig.8). The fraction of transformed beta and $\alpha^{6}$ phase increased with the temperature (Fig.9c), resulting in the simultaneous hardness increase $[7,8]$. The increasing fraction of transformed beta and $\alpha^{6}$ phase formed during the forming process may also decrease the formability of the material, which resulted in the forming failure at temperatures ranging from 900 to $950^{\circ} \mathrm{C}$ [9].

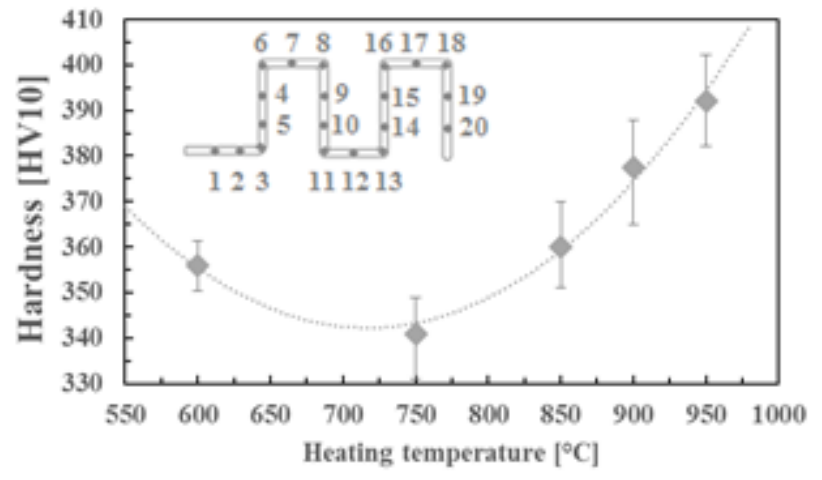

Fig. 8. Effect of heating temperature on post-form strength of formed components.
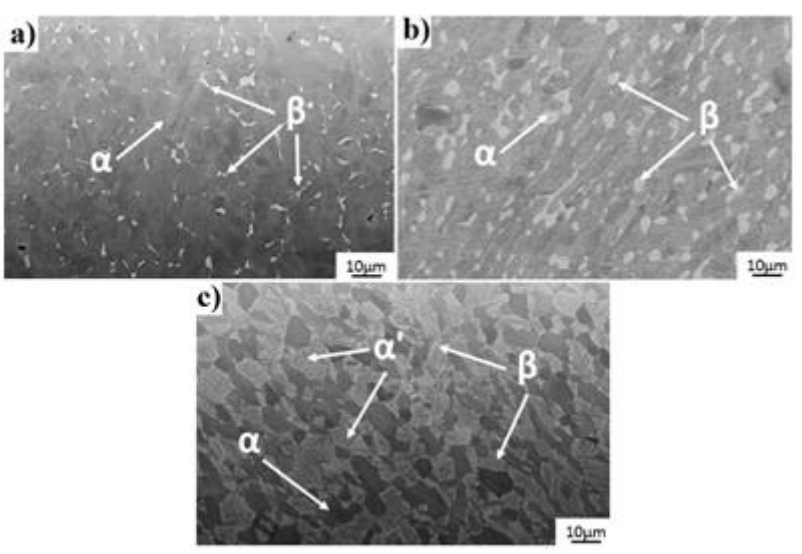

Fig. 9. Microstructures of the Ti6Al4V alloy formed at $600^{\circ} \mathrm{C}$

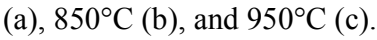

\section{Conclusions}

In this paper, an innovative forming technology to shape Ti6Al4V titanium alloy utilizing low temperature forming tools and a hot blank was studied through uniaxial tensile test and hot stamping process. The uniaxial tensile properties of Ti6Al4V alloy at temperatures from $600^{\circ} \mathrm{C}$ to $900^{\circ} \mathrm{C}$ with the strain rate of $1 \mathrm{~s}^{-1}$ have been obtained. The results of tensile tests showed that the investigated material has a good formability over the testing temperature of $700^{\circ} \mathrm{C}$. It was observed that during deformation at temperatures from $600^{\circ} \mathrm{C}$ to $700^{\circ} \mathrm{C}$, work hardening occurred. As the temperature increase to $750^{\circ} \mathrm{C}$, the hardening rate decreased and the flow stress curve became flat due to recovery. With the temperature increase to $900^{\circ} \mathrm{C}$, an obvious material softening during the tensile test occurred. Ti6Al4Vcomponents were successfully formed at temperatures ranging from $750^{\circ} \mathrm{C}$ to $850^{\circ} \mathrm{C}$. The hardness of formed parts firstly decreased from $357 \mathrm{HV} 10$ at $600^{\circ} \mathrm{C}$ to $341 \mathrm{HV} 10$ at $750^{\circ} \mathrm{C}$ due to recovery and then increased to $392 \mathrm{HV} 10$ at $950^{\circ} \mathrm{C}$ as a result of phase transformation. It was found that through the adjustment of the heating temperature, the post-form mechanical properties can be tailored, which indicates that this new technology has a great potential in forming titanium alloys sheet components. 
The strong support from the Aviation Industry Corporation of China (AVIC) Beijing Aeronautical Manufacturing Technology Research Institute (BAMTRI) for this funded research is much appreciated. The research was performed at the AVIC Centre for Structural Design and Manufacture at Imperial College London.

\section{References}

1. M. Peters, J. Kumpfert, C. Ward, C. Leyen, Adv. Eng. Mater. 5 , 419 (2003)

2. S. Semiation, e. al., Metalworking: Sheet Forming Forming of titanium and titanium alloys (ASM International), 14b, 656 (2006)

3. L. Wang, T. Dean, J. Lin, Proceedings of the $3 r d$ International Conference on Advanced High Strength Steel and Press Hardening (ICHSU2016), W. Scient. 289 (2017)

4. P. Bariani, S. Bruschi, A. Ghiotti, F. Michieletto, CIRP Annals, 62, 251 (2013)

5. T. Maeno, K. Mori, R. Yachi, CIRP Annals, 66, 269 (2017)

6. Z. Hamedon, K. Mori, T. Maeno, Y. Yamashita, NMSTU, 5, 12 (2013)

7. S. Jadhav e. al, IOP Conf. Ser.: Mater. Sci. Eng. 201, 1 (2017)

8. T. Furuhara, B. Poorganji, H. Abe, T. Maki, JOM, 59, 64 (2007)

9. A. Rollett, F. Humphreys, G. Rohrer, M. Hatherly, Recrystallization and related annealing phenomena (Elsevier, 2004). 